\title{
NILAI-NILAI KEASWAJAAN DALAM KRITIK KH. M. HASYIM ASY'ARI TERHADAP PEMIKIRAN WAHABI
}

\author{
Muhammad Abror Rosyidin \\ Tebuireng Institute for Islamic Studies \\ E-mail: Abror30031994@gmail.com
}

\begin{tabular}{|c|c|c|}
\hline Received & Revised & Accepted \\
\hline 4 July 2021 & 2 Agustus 2021 & 20 September 2021 \\
\hline
\end{tabular}

\section{ASWAJA VALUES IN CRITIQUES OF KH. M. HASYIM ASY'ARI ON WAHHABISM}

\begin{abstract}
This study aim to explore: (1) The emergence of Wahhabis and its development in Indonesia, (2) Aswaja values in critiques of KH. M. Hasyim Asy'ari against Wahhabism, and (3) SocioHistorical-Political Analysis of KH. M. Hasyim Asy'ari to the Wahhabism. This study uses a qualitative approach to literature study with analytical descriptive data analysis. The research design used is to do a literature study that is in accordance with the discussion and conduct interviews that are needed to complete the data with several informants. The next step is to reduce the data obtained, analyze, and obtain conclusions according to the research focus. The results of this study indicate Aswaja values according to KH. M. Hasyim Asy'ari from Wahhabism that need to be clarified, namely: (1) the meaning of the term "heresy", (2) claiming to be a followers of Ibn Taimiyah, (3) prayers for the dead do not arrive, (4) intercession does not exist, (5) reckless in interpreting the verses of the Qur'an, (6) the doctrine of returning to the Qur'an and Sunnah, (7) not paying attention to scientific sanad, (8) prohibition of following madzhab and taqlid.
\end{abstract}

Keywords: Aswaja Values, Hasyim Asy'ari, criticism, and Wahhabism.

\begin{abstract}
Abstrak
Penelitian ini bertujuan untuk menggali: (1) Kemunculan Wahabi dan Perkembangannya di Indonesia, (2) Nilai Aswaja dalam Kritik KH. M. Hasyim Asy'ari terhadap Wahabisme, dan (3) Analisis Sosial-Sejarah-Politik KH. M. Hasyim Asy'ari terhadap Wahhabisme. Penelitian ini menggunakan pendekatan kualitatif dengan studi kepustakaan dengan analisis data deskriptif analitis. Desain penelitian yang digunakan adalah melakukan studi kepustakaan yang sesuai dengan pembahasan dan melakukan wawancara yang diperlukan untuk melengkapi data dengan beberapa informan. Langkah selanjutnya adalah mereduksi data yang diperoleh, menganalisis, dan memperoleh kesimpulan sesuai dengan fokus penelitian.
\end{abstract}


Hasil penelitian ini menunjukkan nilai Aswaja menurut KH. M. Hasyim Asy'ari dari Wahhabisme yang perlu diluruskan, yaitu: (1) pengertian istilah "bid'ah", (2) mengaku pengikut Ibnu Taimiyah, (3) doa untuk orang yang sudah meninggal tidak sampai. , (4) tidak ada syafaat, (5) sembrono dalam menafsirkan ayat-ayat al-Qur'an, (6) doktrin kembali kepada al-Qur'an dan sunnah, (7) tidak memperhatikan sanad ilmiah, (8 ) larangan mengikuti madzhab dan taqlid.

Kata kunci: nilai Aswaja, Hasyim Asy'ari, kritik, dan Wahhabisme.

\section{Pendahuluan}

Semenjak abad ke-13, terutama setelah jatuhnya Baghdad ke tangan tentara Hulagu Khan, dunia Islam terus menerus mengalami kemunduran. Kemunduran tersebut telah mencakup segala bidang, baik bidang intelektual, sosial, terlebih lagi dalam bidang keagamaan. Lalu bermunculan analisis mengenai apakah penyebab kemunduran Islam (Inhidar al-Islam). Kemudian ada analisis mengenai pengaruh tarekat yang berkembang semakin dalam yang mengakibatkan akidah umat Islam bercampur baur dengan bid'ah dan khurafat, Tuhan didekati dengan perantara syaikh atau para wali. Hal itu dianggap mengakibatkan umat Islam hidup dalam keadaan jumud, di mana sikap taklid sudah menyatu dalam kehidupan mereka, karena ada ijtihad dianggap telah tertutup diterima secara umum. Hal ini memunculkan tuduhan bahwa umat Islam buta terhadap ajaranajaran Islami yanng murni, yakni ajaran-ajaran yang tertera dalam Al-Qur'an dan Sunnah.

Dalam keadaan masyarakat yang seperti ini, pada pertengahan abad ke-18, di Jazirah Arab muncul satu gerakan yang berusaha memurnikan ajaran Islam dengan semboyan kembali kepada Islam yang asli seperti yang dianut dan dipraktikkan pada zaman Nabi SAW, Shahabat, serta Tabi'in sempai abad ke-3 Hijriah. Gerakan ini dalam sejarah terkenal dengan nama "Gerakan Wahabi" yang dilancarkan oleh tokohnya bernama Muhammad ibn Abdul Wahab. ${ }^{1}$ Mereka juga menamakan diri dengan golongan salafi.

Salaf adalah sebuah bentuk penisbatan kepada as Salaf, yang secara bahasa bermakna orang-orang yang mendahului atau hidup sebelum kita. Adapun makna terminologi as Salaf adalah generasi yang dibatasi oleh sebuah penjelasan Rasullullah SWA, "Sebaik-baiknya manusia adalah yang hidup di masaku, kemudian yang mengikuti mereka (tabi’in), kemudian yang mengikuti mereka (tabi’i at tabi'in)", (HR. Bukhori Muslim).

Dari hadis ini maka yang disebut dengan golongan Salaf, adalah para sahabat Rasulullah SAW, para tabi'in dan kemudian tabi'i at tabiin. Masa tiga kurun ini disebut dengan al Qurun al Mufadhadhalah (kurun yang mendapatkan keutamaan). Sebagian ulama kemudian menamabahkan lafal ash Shalih setalah lafal as Salaf, sehingga menjadi as Salaf ash Shalih sebagai pembeda dengan generasi setelahnya, yaitu al Khalaf. Maka ketika menyebut kata Salafi, maka seharusnya makna asalnya adalah orang yang mengaku mengikuti jalan yang ditempuh sahabat-sahabat Nabi SAW, para tabi’in dan tabi’i at tabiin.

${ }^{1}$ Ris'an Rusli, Pembaharuan Pemikiran Modern Dalam Islam, (Jakarta: Rajawali Pers), Cet. II, 2014 , hal. 1. 
Namun, ada golongan tertentu yang kemudian mengaku meniti jalan para ash Salaf ash Shalih, dengan doktrin memurnikan agama dan kembali ke al Quran dan Sunnah. Mereka menisbatkan kata Salafi kepada kata Wahabi, sehingga Salafi kemudian dipakai untuk kata yang merujuk kepada golongan mereka. ${ }^{2}$ Lalu siapa Wahabi dengan ajaran Wahabisme itu?

Wahabi atau Wahabiyah adalah sebutan suatu komunitas atau kelompok yang dimaksudkan kepada pelopornya Muhammad ibn Abdul Wahab yang muncul di Nejed pada sekitar abad ke $12 \mathrm{H} / 18 \mathrm{M}^{3}$ Sekte ini dinisbatkan langsung kepada sang pendiri yang lahir pada $1115 \mathrm{H} / 1703 \mathrm{M}$ yang merupakan putra dari seorang qodli (hakim) di Huraimilah Uyainah, Abdul Wahab ibn Sulaiman an Najdi. Ayahnya adalah seorang pakar fikih Madzhab Hanbali kenamaan di tanah Nejed. Ia pernah belajar kepada Syaikh Sulaiman Ibn Sulaiman al Kurdi, Syaikh Muhammad Hayat as Sindi, dan tentu kepada ayahnya dan kakaknya, Sulaiman ibn Abdul Wahab, yang juga merupakan ulama madzhab Hanbali.

Namun, sebenarnya ada yang tidak beres dengan penisbatan kelompok ini kepada istilah Wahabiyah atau golongan yang mengikuti ajarab Wahab, karena Wahab atau Abdul Wahab adalah nama ayahnya, sedangkan nama pelopornya adalah Muhammad yang kebetulan adalah putra seorang laki-laki bernama Abdul Wahab. Seharunya ajaran ini disebut Muhammadiyah, bukan Wahabiyah. Namun, ada kerancuan jika menyebutnya Muhammadiyah, karena dikhawatirkan dinisbatkan kepada Nabi Muhammad SAW. Kesalahan penisbatan ini berlanjut hingga sekarang.

Gerakan kelompok ini mencoba untuk melakukan purifikasi (pemurnian) ajaran agama Islam dengan semboyannya; kembali ke ajaran pokok al Quran dan Hadis. Dalam pandangan mereka, umat Islam saat ini tengah berada dalam kesesatan akidah yang amat parah. Lantaran selalu mengangung-agungkan para aulia, menziarahi kuburan mereka, dan meminta syafaat dari mereka, serta melakukan hal-hal yang, bagi mereka, tidak ada referensinya dalam kitab suci maupun ajaran Nabi SAW, atau artinya melakukan perbuatan bid'ah dalam agama. $^{4}$

Setelah mendapatkan pertentangan dari keluarganya, khususnya sang ayah dan kakaknya, Ibn Abdil Wahab pindah-pindah dari Huraimilah ke Kota Uyainah, lalu menikah dengan perempuan kaya di sana. Dari sana, ia juga mendapatkan pengusiran oleh warga kota, sehingga ia pindah ke Dir'iyah. Di sanalah botol bertemu dengan tutupnya, di mana ia berjumpa dengan Muhammad Ibnu Sa'ud, Emir Dir'iyah saat itu. Ia disambut dengan hangat. Dari pertemuan itulah ekspansi ideologis didukung oleh gerakan politik keluarga Sa'ud ajaran ini menyebar sampai ke daerah-daerah di luar Nejed. ${ }^{5}$ Muhammad Ibn Abdil Wahab dibaiat

\footnotetext{
${ }^{2}$ Syaikh Idahram, Sejarah Berdarah, Sekte Salafi Wahabi: Mereka Membunuh Semuanya, termasuk Para Ulama, (Bantul: Pustaka Pesantren, 2011), Cet. XVII, hal. 24-25

${ }^{3}$ Nurchalis Majid, Islam, Kemoderenan, dan Keindonesiaan, (Bandung: Mizan, 2008), hal. 365

${ }^{4}$ Muhammad Hafidz Diyab, Asalafiyun wa as Siyasah, (Kairo: al Haiah al Misriyyah al Ammah li al Kitab, 2015, hal. 127.

${ }^{5}$ Syaikh Idahram, Sejarah Berdarah, Sekte Salafi Wahabi: Mereka Membunuh Semuanya, termasuk Para Ulama, (Bantul: Pustaka Pesantren, 2011), Cet. XVII, hal. 37.
} 
menjadi imam urusan agama dan Ibnu Sa'ud sebagai emir pada 1744. Ini sebagai penanda berdirinya sebuah negara,yang dikenal sekarang dengan Negara Saudi pertama.

Menurut Ahmad Sarwat, Muhammad bin Abdul Wahab tidak menulis buku yang tebal dan berjilid-jilid seperti para fuqaha atau filsuf muslim. Ia hanya menulis beberapa risalah atau makalah pendek yang dikumpulkan menjadi "kitab at-tauhid" yang kini menjadi rujukan para ulama. Di dalamnya terdapat larangan membuat bangunan di atas kuburan dan memasang larangan lampu di dalamnya. Kaum Wahabi juga melarang orang melakukan tindakan yang menjerumuskan mereka pada syirik, seperti melarang ber-tawassul dengan menggunakan nama orang sholeh.

Muhammad ibn Abdil Wahab mengomandoi para pengikutnya untuk mengamalkan pemahaman mereka sendiri atas ayat-ayat itu. Bahkan mereka diyakinkan untuk lebih mempercayai pemahaman dan penafsiran mereka sendiri terhadap ayat-ayat Al Quran daripada penafsiran para ulama yang terpercaya yang termaktub dalam kitab-kitab klasik. Bahkan dalam surat-suratnya kepada para pengikutnya, ia mengatakan "Berijtihadlah menurut pemahaman dan pendapat kalian. Lalu berhukumlah dengan apa saja yang kalian anggap sesuai dengan agama ini!". Mereka menafsirkan ayat-ayat sekehendak akal dan nafsunya, tidak lagi didasarkan pada penafsiran Rasulullah, sahabat, ulama salaf, dan ulama tafsir. ${ }^{6}$

Mereka tak segan-segan melakukan tindakan keras dalam menyebarkan pahamnya itu. Ketika memasuki kota Tha'if pada 1924, kaum wahabi melakukan penjaharan dan menyeret para qadi (hakim agama) yang menolak paham Wahabiyah, dan bahkan membunuh mereka. Mereka juga hendak meratakan kuburan Rasulullah SAW dan menghancurkan kuburan para sahabat serta bangunan kuburan tokoh-tokoh sufi yang sering dikunjungi masyarakat.

Perbuatan yang tidak terpuji ini dilakukan setelah kekuasaan mereka dapatkan, berdiri dan mengambil paham Wahabiyah sebagai satu-satunya mahdzab resmi Negara. Mereka tidak hanya menolak praktik dan ajaran sufi, bahkan menganggapnya sebagai bid'ah dan syirik. Memang ini konsekuensi dari sikap teologis Muhammad bin Abdul Wahab yang tegas dengan prinsip tauhid (pengesaan Allah). Begitu juga dengan sikap taqlid di kalangan umat Islam, dianggapnya sebagai penyebab kemunduran Islam.

Dakwah mereka tidak cukup dilakukan dengan ajakan untuk mempercayai ajaran mereka. Namun, Muhammad Ibn Abdil Wahab dan Ibn Sa'ud melakukan ekspansi ke berbegai daerah di sekitar Nejed. Penyebaran ajaran Wahabi dibayar dengan penumpasan darah kaum muslimin di berbagai daerah, misalnya penyerangan terhadap penduduk Karbala, Thaif, Mekkah, Madinah, Riyadl, dan daerah lain. Bahkan karena dendam masa lalu, Ibn Abdil Wahab rela menghancurkan Kota Uyainah, tanah kelahirannya, dan membunuh Emirnya Utsman ibn Hamad ibn Mu'ammar. Bahkan mereka menyerang Jamaah haji dari Yaman dan Iran, menghalangi umat Islam melakukan ibadah haji dan membunuhi banyak ulama di Hijaz.

\footnotetext{
${ }^{6}$ Muhammad Faqih Ibn Abdul Jabbar Maskumambang, an Nushush al Islamiyah fi Raddi ala Madzhab al Wahabiyah, (Bogor: Sahifah li ath Thiba'ah wa an Nasyr, 2016) Cet. III, hal. 35-36.
} 
Kisah kekejaman mereka bahkan ditulis oleh Mufti Mekkah bermadzhab Syafi'i, Syaikh Zaini Dahlan (w. 1304 H) dalam kitabnya Umara al Balad al Haram. Mereka bahkan meratakan pemakaman Baqi yang diisi dengan makam para istri dan putra-putri Rasulullah. Situs-situs sejarah Islam juga dihancurkan. Bahkan makam Rasulullah SAW juga rencananya akan diratakan dengan tanah. ${ }^{7}$ Rencana inilah yang paling mendapatkan reaksi dari muslim di belahan dunia, termasuk ulama-ulama Nusantara yang kala itu dipelopori oleh KH. Wahab Chasbullah, KH. Hasyim Asy'ari, KH Asnawi Kudus, dan lain-lain, hingga terbentuknya Komite Hijaz untuk melobi agar rencana itu tidak dilakukan, termasuk juga agar pemaksaan asas tunggal Wahabi terhadap umat Islam di Hijaz dan melarang kebebasan bermadzhab tidak terjadi. ${ }^{8}$ Sampai kemudian Negara Arab Saudi, atau Kerajaan Arab Saudi diakui oleh Inggris dan dunia internasional pada 1932 penanda pengaruh Wahabi sudah mutlak di sebagian besar wilayah Jazirah Arab.

Charles Allen dalam God's Terrorists, The Wahhabi Cult and The Hidden Roots of Modern Jihad, menyebut sejak awal tahun 1980-an terjadi perkembangan dakwah yang agak berbeda di Indonesia. Penggerak dakwah mulai berdatangan dari luar negeri, mencoba membenturkan dengan Islam Tradisional yang sudah berkembang di Nusantara. Mulai bermunculan, kelompok-kelompok seperti Ikhwanul Muslimin, Jama'ah Tabligh, Hizbut Tahrir, Jama'ah Islamiyah, dll. Salafi mulai populer di Indonesia dibawa oleh Ja'far Umar Thalib dan kawan-kawannya. Namun, sebenarnya sudah disinggung sebelumnya, bahwa Salafi sebenarnya adalah nama lain atau penyebutan lain dari Wahabi yang berkembang sejak hampir 3 abad lalu. ${ }^{9}$

Dilihat dari kemiripan manhaj-nya, diduga sebagian paham Wahabi sudah berpengaruh dan masuk ke masyarakat Nusantara dibawa oleh ulama dan tokoh Sumatera Barat pada awal abad ke-19. Kata sebagian sepertinya memang pas, karena ulama Sumetara Barat itu tidak mengambil mentah-mentah ajaran Wahabi, tetapi hanya terinspirasi dengan spirit pembaharuannya saja, ketika mereka bersinggungan dengan Wahabi di Mekkah saat menunaikan ibadah haji.

Gerakan inilah yang kemudian menjadi perkembangan awal ajaran Wahabisme di bumi Nusantara, yang kemudian dikenal dengan kaum Paderi. Salah satu tokohnya adalah Tuanku Imam Bonjol. Gerakan Kaum Padri ini terjadi pada kurun 1803-1832. Syaikh Surkati dengan al-Irsyadnya dan KH. Ahmad Dahlan dengan Muhammadiyahnya juga hanya mengambil spririt pembaharuannya saja, tidak mengambil secara keseluruan doktrin Wahabi kepada umatnya. Maka, ada benarnya jika pergerakan-pergerakan Islam modern yang lahir lebih awal dan berkembang di Indonesia, seperti Muhammadiyah, Persis, dan al Irsyad hanya memiliki kesamaan ide - bukan paham - dengan kelompok Salafi Wahabi. ${ }^{10}$

\footnotetext{
${ }^{7}$ Lihat secara lengkap di Syaikh Idahram, Sejarah Berdarah Sekte Salafi Wahabi, (Bantul Pustaka Pesantren, 2011).

${ }^{8}$ Ahmad Mubarok Yasin dan Fathurrohman Karyadi, Profil Pesantren Tebuireng, (Jombang: Pustaka Tebuireng, 2011), hal. 59.

9 Syaikh Idahram, Sejarah Berdarah, Sekte Salafi Wahabi: Mereka Membunuh Semuanya, termasuk Para Ulama, (Bantul: Pustaka Pesantren, 2011), Cet. XVII, hal. 39.

${ }^{10}$ Ibid, hal. 42-43
} 
Kesamaan ide atau spirit yang dimaksud adalah semangat untuk memurnikan ajaran Tauhid, yang disinyalir oleh mereka mengandung Tahayyul, Bid'ah, dan Khurafat (TBC), karena dianggap masih dipengaruhi oleh Animisme, Dinamisme, Hindu, dan Budha. Namun, sebagai senior pergerakan pemurnian tauhid di Indonesia, Muhammadiyah, Persis, dan al Irsyad, tidak dianggap sesama oleh Salafi Wahabi yang datang belakangan. Bahkan juga dianggap sesat, kafir, dan bid'ah oleh mereka. Tidak hanya itu, sesama mereka saja sekarang ini tengah tidak akur, alias saling menuduh. ${ }^{\text {I }}$ Di antara tokohnya, ada Syarif Fuad Hazza, Abu Haidar, Khalid Syamhudi, Yazid Abdul Qadir Jawwas, Aris Munandar, Muhammad Umar Sewed, Luqman Ba'abud, dll.

Secara garis besar Salafi Wahabi terbagi menjadi dua faksi, yaitu Salafi Haraki dan Salafi Yamani. Salafi Haraki masuk ke Indonesia lebih awal dari pada Salafi Yamani. Ja'far Umar Thalib adalah perintis Salafi Yamani di Indonesia. Salafi Haraki adalah gerakan dakwah Salafi yang menerapkan metode pergerakan (harakah), metode ini, walaupun ada kesamaan dan perbedaan, diilhami oleh gerakan dakwah seperti Ikhwanul Muslimin (IM), Hizbut Tahrir (HT), Jama'ah Tabligh (JT), Jama'ah Islamiyah (JI), Negara Islam Indonesian (NII). Sementara Salafi Yamani, tidak terikat dengan jama'ah tertentu, alias independen. ${ }^{12}$

Hadratussyaikh KH. M. Hasyim Asy'ari adalah ulama yang sangat diakui keilmuan dan akhlaknya. Lebih dikenal sebagai Mbah Hasyim, adalah ulama yang disegani dan karismatik. Berjuang untuk Islam dan kemerdekaan Indonesia. Berbicara tentang pemikiran dan perjuangan sanga Guru Besar, tak bisa terlepas dari sejarah hidupnya. Terlahir dengan nama Muhammad Hasyim pada tanggal 24 Dzulqa'dah $1287 \mathrm{H}$. atau bertepatan dengan 14 Februari $1871 \mathrm{M}$. Hasyim kecil dilahirkan di Gedang, sebuah dusun kecil di utara Jombang (sekarang berada di timur Pondok Pesantren Bahrul Ulum Tambakberas), putra ketiga dari sebelas bersaudara dari pasangan KH. Asy'ari dan Nyai Hj. Halimah. Kiai Asy'ari adalah menantu Kiai Utsman, pendiri dan pengasuh Pesantren Gedang. ${ }^{13}$ Kiai Hasyim merupakan pendiri Nahdlatul Ulama (NU) dan juga pendiri Pesantren Tebuireng Jombang.

Kiai Hasyim menulis beberapa literatur mengenai banyak disiplin ilmu, seperti akhlak, adab, masalah-masalah ushuluddin, fikih, dan lain sebagainya yang sebagian besar merupakan tanggapan terhadap keadaan masyarakat dan kondisi sosio-politik pada saat itu. Temasuk juga mengomentari soal perkembangan aliran-aliran Islam yang berkembang di masyarakat pada itu, salah satunya perkembangan ajaran pembaharuan. Untuk itu, peneliti tertarik untuk mengumpulkan beberapa komentar Kiai Hasyim tentang ajaran-ajaran Wahabisme di dalam beberapa literatur yang ditulis oleh pemimpin umat Islam pertengahan abad 19 tersebut.

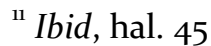

${ }^{12}$ Ibid, hal. 59

${ }^{13}$ Mukani, Biografi dan Nasihat Hadratussyaikh KH. M. Hasyim Asy'ari, cet 1, (Jombang: Pustaka Tebuireng, 2015), 4.
} 


\section{Hasil dan Pembahasan}

\section{Pandangan KH. Hasyim Asy'ari}

Di beberapa tulisan Hadratussyaikh KH. M. Hasyim Asy'ari mengkritisi beberapa pemahaman yang dikembangkan oleh Wahabi dan turunannya. Memang tidak ada istilah Wahabi yang dikutip secara langsung oleh Kiai Hasyim. Namun, dari setting sosial yang ada dan latar belakang keadaan sosio politik pada saat itu, menandakan upaya Kiai Hasyim untuk meluruskan ajaran-ajaran dan tuduhantuduhan Salafi Wahabi kepada sesama umat Islam yang berbeda pendapat.

Ulasan mengenai hal itu, tertera dalam bebera kitab dan risalah yang ditulis oleh Kiai Hasyim, di antaranya ada di Risalah Ahlussunnah wal Jama'ah, an Nur al Mubin fi Mahabbati Sayyid al Mursalin, Risalah fi Ta'kid al Akhdi bi Madzahib al Aimmah al Arba'ah, dan Risalah Jawazu at Taqlid. Apa yang disampaikan oleh Kiai Hasyim dapat diambil nilai-nilai ajaran Ahlussunnah wal jama'ah dan corak Islam yang dianut oleh Kiai Hasyim dan tentu saja berkaitan dengan organisasi yang didirikannya yaitu NU yang moderat. Nilai-nilai pendidikan Aswaja dalam kitabkitabnya ini ditulis oleh beliau terpisah dalam beberapa literatur, karena memang ditulis berdasarkan pada apa yang masyarakat butuhkan. Artinya berbasis kasus. Berikut beberapa ulasan yang ditemukan peneliti:

\section{Pemaknaan Istilah Bid'ah}

Kiai Hasyim mengutip pengertian Bid'ah menurut Syaikh Zaruq dalam kitab Uddatul Murid, dari sudut pandang terminologi syara' adalah: menciptakan hal baru dalam perkara agama yang seolah-olah ia merupakan bagian dari urusan agama. Padahal sebenarnya bukan, baik dalam tataran wacana, penggambaran, maupun hakikat.

Kiai Hasyim menganalisis dua hadis yang dijadikan rujukan oleh kaum Wahabi dalam menentang hal-hal yang mereka anggap bid'ah, dan juga dikutip dari Syaikh Zaruq, yaitu:

"Barang siapa yang menciptakan suatu hal baru, dalam urusan kami ini Juga hadis:

(urusan agama), yang bukan bagian dari agama, maka ia tertolak".

"Setiap perkara yang diada-adakan adalah bid'ah".

Parameter yang terakandung di dalam dua hadis di atas, Kiai Hasyim merujuk kepada tindakan mengubah hukum dengan cara menganggap sesuatu yang bukan merupakan bagian dari ibadah dianggap sebagai sebagai bagian dari ibadah. Jadi menuduh bid'ah tidak bisa diasal, atau tidak bisa diada-adakan. Kerena boleh jadi perkara itu telah tercakup dalam pokok-pokok (ushul) Syariat. Bisa jadi juga, perkara itu telah terkover dalam cabang-cabang syariat (furu') sehingga perkara itu terkiyaskan kepada-Nya.

Syaikh Zarruq mengatakan ada 3 parameter bid'ah. Pertama, perkara itu harus diamati, jika sebagian besar syariat dan ushul-nya mendukung, maka perkara itu tidak bisa disebut bid'ah, karena bagian dari urusan agama. Kedua, mempertimbangkan kaidah-kaidah yang diakui oleh para Imam dan generasi salaf. Ketika kaidah-kaidah itu menunjukkan diperbolehkannya perkara itu, maka boleh, jika sebaliknya, maka tidak. Ketiga, pemilahan yang didasarkan pada 
Syawahid (saksi-saksi) hukum. Parameter ini terbagi atas enam, yaitu wajib, sunnah, haram, makruh, khilaful aula, dan mubah.

Maka atas dasar ini, terjadi perbedaan pendapat tentang masalah furu'iyah seperti kantor administrasi, berzikir dengan jahr (suara keras), berkumpul dan berdoa bersama. Permasalahan tersebut berakar dari tidak ada anjuran secara jelas dalam nash hadis, tetapi ada informasi yang menyebutkan bahwa hal itu pernah dilakukan oleh generasi salaf. Maka Kiai Hasyim melihat ini sebagai bukti untuk tidak gampang menuduh bid'ah bagi yang memiliki pandangan lain. Hal itu, berdasarkan pada kaidah di mana mujtahid tidak bisa melanggar ijtihadnya sendiri. Seorang juga tidak bisa menyebut yang berbeda dengannya dengan predikat Bid'ah. Konsekuensi dari saling mem-bid'ah-kan ini, tentu penyebutan terhadap seluruh umat Islam dengan label Bid'ah. ${ }^{14}$

Maka soal bid'ah ini, Kiai Hasyim mengkritik kelompok yang sangat mudah melabeli sesama muslim dengan bid'ah hanya kerena amalannya tidak sama atau tidak sependapat dengan mereka. Karena bagi Kiai Hasyim ada diskusi panjang soal menentukan amalan sebuah kelompok, atau seorang muslim, itu bid'ah atau tidak. Tidak ujug-ujug mudah mem-bid'ah-kan. Tentu pemahaman soal hal-hal pokok atau ushuly dan kaidah-kaidah dalam kajian hukum Islam harus dikuatkan agar tidak mudah menjustifikasi sesama.

\section{Kritik Terhadap Golongan yang Mengaku Pengikut Ibn Taimiyah}

Dalam kitab an Nur al Mubin fi Mahabbati Sayyid al Mursalin, Hadratussyaikh KH. M. Hasyim Asy'ari mengkritik tuduhan bid'ah dan syirik kepada umat Islam yang mengamalkan tawasul, istighosah, dan meminta syafa'at melalui perantara Nabi Muhammad SAW, para wali, dan orang-orang saleh. Secara khusus Kiai Hasyim mengkritik pendapat Ibn Taimiyah (ulama panutan Wahabi), terhadap permasalahan bid'ah tawasul dengan mengutip stetemen Imam Taqiyuddin as Subkhi.

Menurut Kiai Hasyim, wasilah adalah apa saja yang dijadikan oleh Allah SWT sebagai sebab untuk mendekatkan diri di sisi-Nya dan penghubung untuk mendapatkan kebutuhan-kebutuhannya dari Allah. Tawasul ada dua macam, tawasul dengan amal-amal saleh, dan tawasul dengan orang-orang yang memiliki keutamaan-keutamaan. Mayoritas umat Islam memperbolehkan tawasul jenis kedua, sedangkan ada sedikit golongan yang melarangnya.

Mengutip stetemen Imam Taqiyuddin as Subkhi, Kiai Hasyim menyebutkan bahwa ulama yang getol memberikan penilaian bid'ah terhadap amalan tawasul ini, yakni Ibnu Taimiyah. Selain itu, Ibn Taimiyah adalah ulama yang dari masa ulama salaf dan khalaf yang pertama kali menentang tawasul dan istighosah. Sampai-sampai dikatakan oleh as Subkhi kedatangan Ibn Tamiyah dengan pendapat-pendapatnya yang menyalahi mayoritas ulama, sebagai peringatan terhadap ahli Islam (ulama). ${ }^{15}$

\footnotetext{
${ }^{14}$ Hadratussyaikh KH. M. Hasyim Asy'ari, Risalah Ahlussunnah wa al Jama'ah, (Jombang: Pustaka Warisan Islam), hal. 5-8.

${ }^{15}$ Hadratussyaikh KH. M. Hasyim Asy'ari, an Nur al Mubin fi Mahabbati Sayyidi al Mursalin, (Jombang: Pustaka Warisan Islam Tebuireng), hal. 69-70.
} 
Menurut Kiai Hasyim, meminta pertolongan Allah (istighosah), meminta syafaat, dan tawasul dengan perantara atau penghubung (intisab) pada Nabi SAW, para wali dan orang-orang saleh, bukan berarti meminta selain kepada Allah SWT. Namun, fakta bahwa mereka adalah hamba-hamba Allah yang dekat denganNya, dengan ketinggian derajat mereka, kesucian ruh mereka, kebersihan jiwa mereka, tentu mereka lebih didengar dari pada kita.

Hadis dari Umar bin Khattab ra. yang menunjukkan kebolehan bertawasul tercantum dalam al Mustadrak yang disusun Imam Al Hakim:

"Ketika Nabi Adam terpeleset melakukan kesalahan, maka berkata, "Hai Tuhanku, aku memohon kepada-Mu dengan haq Muhammad, Engkau pasti mengampuni kesalahanku." Allah berfirman. "Bagaimana kamu mengetahui Muhammad, padahal belum Aku ciptakan?” Nabi Adam berkata: "Hai Tuhanku, karma Engkau ketika menciptakanku dengan tangan kekuasaan-Mu dan meniupkan kepadaku ruh dari-Mu, aku mengangkat kepalaku kemudian aku melihat ke atas tiang-tiang Arasy tertulis 'Lailahaillah Muhammad Rasulullah'. Kemudian mengerti, sesungguhnya Engkau tidak menyandarkan nama-Mu, kecuali makhluk yang paling Engkau cintai." Kemudian Allah berfirman: "Benar engkau, hai Adam. Muhammad adalah makhluk yang paling Aku cintai Apabila kamu memohon kepada-Ku dengan hak Muhammad, maka Aku mengampunimu, dan andaikata tidak karena Muhammad, maka Aku tidak menciptakan mu" (HR. al-Hakim).

Imam Al Hakim menklasifikasikan hadis tersebut dengan shahih al isnad atau sanadnya shahih. Kiai Hasyim juga mengaku heran dengan kontradiksi pemikiran Ibnu Taimiyah antara satu pendapat dengan pendapat lainnya. Misalnya soal tawasul ini, dalam satu kesempatan, Ibn Taimiyah ber-istidlal dengan satu hadis yang disampaikan oleh dua muridnya Abul Faraj dan Ibnu al Jauzi. Keduanya mengaku mendapatkan sanad hadis itu dari Ibnu Taimiyah sampai ke Maisaroh ra yang berbunyi:

"Dari Maisarah ra, ia berkata, 'Saya berkata kepada Rasulullah: 'Wahai Rasulullah, sejak bilakah engkau menjadi nabi?”. Rasulullah Saw menjawab: "Ketika Allah menciptakan bumi, kemudian Allah bersemayam di langit, lalu Allah ciptakan tujuh langit, Allah menciptakan 'Arsy dan menuliskan di atas kaki 'Arsy: Muhammad utusan Allah, penutup para nabi. Allah menciptakan surga yang didiami Adam dan Hawa, dituliskan namaku di atas pintu-pintunya, dedaunannya, kubah-kubahnya dan kemahnya. Adam antara ruh dan jasad. Ketika Allah menghidupkannya, ia melihat kepada 'Arsy, ia lihat namaku, maka Allah memberitahukan kepada Adam, dia (Muhammad) adalah pemimpin anak cucumu. Ketika setan menggoda Adam dan Hawa, maka Adam dan Hawa memohon pertolongan kepada Allah dengan menyebut namaku (Muhammad)".

Hadis lain juga dikutip oleh Abu Nua'im al Hafidz dalam Dalail an Nubuwwah dengan mengambil sanad dari Abul Faraj dari Umar ibn Khattab: 
"Ketika Adam melakukan kesalahan, ia mendongakkan kepalanya. "Wahai Tuhanku, dengan hak Muhammad, mohon Engkau ampuni aku," ujar Adam. Lalu Adam mendapat pertanyaan lewat wahyu, "Apa dan siapakah Muhammad?" "Ya Tuhanku, ketika Engkau menyempurnakan penciptaanku, aku mendongakkan kepalaku ke arah 'arsy-Mu dan ternyata di sana tertera tulisan "Laa Ilaaha illa Allaah Muhammadun Rasulullaah”. Jadi saya tahu bahwa Muhammad adalah makhluk Engkau yang paling mulia di sisi-Mu. Karena Engkau merangkai namanya dengan nama-Mu," jawab Adam. "Betul," jawab Allah, "Aku telah mengampunimu, dan Muhammad Nabi terakhir dari keturunanmu. Jika tanpa dia, Aku tidak akan menciptakanmu."

Dari dua hadis di atas, bisa jelas arah kritik Kiai Hasyim, yaitu inkonsistensi Ibn Taimiyah dalam berpendapat. Tapi hal itu justru dipakai oleh Kiai Hasyim untuk memberikan interpretasi bahwa Ibn Taimiyah yang disebut Syaikhul Islam oleh para pengikutnya dan pengangumnya, dia sendiri, telah menerima konsep tawasul. Bahkan hadis itu diambil oleh dua orang pengikutnya, Syaikh Abul Faraj dan Ibn Al Jauzi. Maka otomatis, hal itu membantah orang-orang yang menganggap bahwa tawasul adalah syirik dan kufur. Terbantahkan oleh guru rujukan mereka sendiri. Bisa jadi para pengikut Wahabi inilah yang mengada-ada pemikiran Ibn Taimiyah disesuaikan dengan maunya mereka.

إنّ هذا الكلام له وجه : Bahkan kata Kiai Hasyim, Ibnu Taimiyah mengatakan: صحيح, "Sesungguhnya pembicaraan ini mempunyai arah yang benar". Selanjutnya Kiai Hasyim akhirnya menyimpulkan bahwa mereka sebenarnya hanya pura-pura menjadi Salafi dan sok-sokan menjadi Taimy (golongan pengikut Ibn Taimiyah), padahal jauh dari ajaran ulama Salaf ash Shalih dan Ibn Taimiyah itu sendiri. Sehingga Ibn Taimiyah menjadi tertuduh dengan tuduhan yang jelek dan tercoreng namanya, karena dirujuk secara serampangan oleh golongan yang mengaku pengikutnya. ${ }^{16}$

Syaikh Ibnu Taimiyah dalam sebagian kitabnya memperbolehkan tawasul kepada Nabi Muhammad SAW tanpa membedakan apakah beliau masih hidup atau sudah meninggal. Ia berkata, "Dengan demikian, diperbolehkan tawasul kepada Nabi Muhammad SAW dalam doa, sebagaimana dalam hadis yang diriwayatkan oleh Imam Tirmudzi:

"Rasulullah SAW mengajari seseorang berdoa, 'Ya Allah sesungguhnya aku meminta kepadaMu dan bertwassul kepadamu melalui Nabi-Mu Muhammad yang penuh kasih, wahai Muhammad sesungguhnya aku bertawassul denganmu kepada Allah agar dimudahkan kebutuhanku maka berilah aku syafa'at”. Lalu kata Ibn Taimiyah lagi, "Tawasul seperti ini adalah bagus. ${ }^{17}$

\section{Kritik terhadap Anggapan Doa untuk Mayit Tidak Sampai}

Dalam Risalah Ahlussunnah Wa al Jama'ah Kiai Hasyim juga menepis anggapan bahwa mayit tidak dapat mengambil manfaat dari yang hidup. Padahal kalangan ahlussunnah menyepakati hal itu bisa terjadi. seorang yang mati dapat

\footnotetext{
${ }^{16}$ Ibid, hal. 42-43

${ }^{17}$ Ibnu Taimiyah, Majmu'atu al Fatawa, (Beirut: Dar el Fikr, 1980), jilid III, hal. 276
} 
mengambil manfaat dari upaya yang dilakukan oleh orang-orang yang masih hidup dengan dua cara. Pertama, sesuatu yang diupayakan oleh mayit semasa hidupnya. Kedua, doa dan istighfar yang dipanjatkan oleh kaum muslimin untuknya, atau sedekah dan ibadah haji yang diniati untuk si mayit itu.

Perbedaan pendapat muncul, ketika upaya dari orang hidup itu berupa ibadah badaniyah seperti puasa, shalat, membaca al Quran, dan zikir. Jumhur ulama salaf tidak menafikan bahwa hal-hal tersebut bisa sampai kepada mayit. Hanya ada sebagian golongan yang mengatakan itu tidak bisa bermanfaat bagi mayit, sama sekali tidak bisa sampai. Kiai Hasyim menyebut golongan ini dengan "ahli bidah". Mereka ber-istidlal dengan ayat Al Quran:

"Dan bahwasanya seorang manusia tiada memperoleh selain apa yang telah diusahakannya," (QS an Najm: 39).

Padahal pendapat itu tertolak dengan sendirinya oleh ayat itu, di mana Allah hanya menafikan kepemilikan atas suatu yang tidak diusahakannya. Sebenarnya, hasil dari sebuah usaha, milik dari orang yang mengusahakannya. Namun, jika berkehendak, bisa dia berikan kepada orang lain, atau mempertahankannya untuk dirinya sendiri. ${ }^{18}$ Intinya jika upaya-upaya itu oleh yang mengupayakan (yang hidup, atau yang mati ketika hidup), memang dikehendaki untuk diberikan kepada si Mayit ya sah-sah saja, karena itu pilihan.

\section{Kritik Terhadap Anggapan Syafaat itu Tidak Ada}

Dalam kitab yang sama, an Nur al Mubin fi Mahabbati Sayyid al Mursalin, Kiai Hasyim juga menjelaskan kritik terhadap golongan yang mengatasnamakan diri Salafi tetapi mengingkari adanya syafaat. Kiai Hasyim mengutip pembagian syafaat dari Qadli Iyadl dalam kitab asy Syifa fi Ta'rifi Huquqi al Musthafa yang terbagai menjadi lima jenis. Pertama, syafaat khusus dengan perantara Nabi Muhammad SAW. Syafaat ini khusus nanti ketika di hari penghitungan amal di mahsyar, tidak ada yang bisa memberikan syafaat ini kecuali Nabi SAW, atau disebut dengan syafa'at udzma. Untuk syafaat ini, seharusnya tidak ada yang mengingkarinya.

Syafa'at kedua, yakni, saat memasukkan kaum ke surga tanpa hisab, juga khusus dari Nabi SAW. Ketiga, syafa'at untuk kaum yang ditetapkan masuk neraka, lalu Nabi SAW memberikan syafa'at kepada mereka dan kepada siapa saja yang dikehendaki oleh Allah. Keempat, syafaat kepada orang-orang yang penuh dosa, dan telah masuk neraka. Mereka mendapatkan syafaat untuk masuk surga dengan perantara Nabi SAW, para nabi yang lain, para malaikat, dan orang-orang saleh. Kelima, syafa'at yang diberikan untuk ahli surga yang dinaikkan derajat surgawinya, tapi amal-amalnya tidak cukup untuk mencapainya. ${ }^{19}$

Sebelum memberikan kritiknya, Kiai Hasyim terlebih dahulu memberikan beberapa dalil tentang syafa'at baik dari Al Quran maupun Hadis. Namun, bukan kapasitas penulis di sini untuk menjelaskan dalil-dalil itu, karena tugas penulis lebih pada penjelasan tentang bagaimana Kiai Hasyim mengkritik pemikiran yang

\footnotetext{
${ }^{18}$ Hadratussyaikh KH. M. Hasyim Asy’ari, Risalah Ahlussunnah wa al Jama'ah, (Jombang: Pustaka Warisan Islam), hal. 39-40

${ }^{19}$ Ibid, hal. 75-76
} 
saat itun sedang berseberangan dengan mayotitas umat Islam. Untuk dalil bisa dibaca sendiri di kitab an Nur al Mubin fi Mahabbati Sayyidi al Mursalin, baik versi Arab maupun versi terjemah Bahasa Indonesia dalam Bab 29 tentang Syafa'at.

Ada sekitar 21 ayat Al Quran dan hadis Rasulullah SAW yang dikutib Kiai Hasyim dalam bab tersebut dengan maksud untuk menguatkan pendapat beliau bahwa syafa'at itu ada dan dijelaskan oleh agama. Yang menarik dalam beberapa hadis itu, adalah yang secara khusus beliau nukil untuk mengkonter pendapat bahwa syafa'at itu tidak ada. Beliau merasa heran terhadap sebagian orang yang mengatakan, syafa'at adalah perkara yang dilarang dan tidak ada gunanya. Dalil yang dipakai oleh mereka adalah firman Allah SWT:

"Dan jagalah dirimu dari (azab) hari (kiamat, yang pada hari itu) seseorang tidak dapat membela orang lain, walau sedikitpun; dan (begitu pula) tidak diterima syafa'at dan tebusan dari padanya, dan tidaklah mereka akan ditolong." (QS. Al Baqarah: 48)

Berilah mereka peringatan dengan hari yang dekat (hari kiamat yaitu) ketika hati (menyesak) sampai di kerongkongan dengan menahan kesedihan. Orang-orang yang zalim tidak mempunyai teman setia seorangpun dan tidak (pula) mempunyai seorang pemberi syafa'at yang diterima syafa'atnya. (QS. Al Mukmin: 18)

"Apa yang menyebabkan kamu masuk ke dalam (neraka) Saqar Mereka menjawab, Dahulu kami tidak termasuk orang-orang yang melaksanakan shalat. Dan kami (juga) tidak memberi makan orang miskin. Bahkan kami biasa berbincang untuk tujuan yang batil, bersama orang-orang yang membicarakannya. Dan kami mendustakan hari pembalasan. Sampai datang kepada kami kematian. Maka tidak berguna lagi bagi mereka syafaat (pertolongan) dari orang-orang yang memberikan syafaat”. (QS. Al Mudatsir: 42-48)

Ketiga ayat di atas, dipakai oleh mereka untuk menolak anggapan adanya syafa'at. Uniknya, Kiai Hasyim justru mengkonter pemikiran itu, dengan dalil yang dikeluarkan oleh mereka sendiri. Kiai Hasyim membuat sebuah kesimpulan yang sebenarnya sangat mudah untuk dicerna secara pikiran telanjang. Pertama, ayat-ayat di atas, menunjukkan bahwa syafa'at tidak berguna bagi orang-orang musyrik yang memang di-nash oleh Allah tidak mendapatkan syafa'at-Nya. Jadi khitab dalam ayat tersebut bukanlah umat Islam, karena rahmat Allah di dunia dan akhirat, dicurahkan untuk mereka.

Kedua, simpel saja, ayat-ayat itu bermaksud untuk menghapuskan syafa'at yang ditetapkan sendiri oleh orang-orang musyrik dan yang serupa dengan mereka, seperti para ahli bid'ah yang mengira bahwa orang-orang seperti mereka dapat memberikan syafa'at kepada sesama manusia di sisi Allah SWT di akhirat. Tentu lagi-lagi ini tidak ditujukan untuk muslim, apalagi setingkat nabi, wali, dan orang-orang saleh, yang jelas-jelas lebih dekat derajatnya di mata Allah, dalam kadar takwa dan taatnya. ${ }^{20}$

\footnotetext{
${ }^{20}$ Ibid, hal. 80
} 


\section{Kritik terhadap Kesembronoan dalam Menafsiri Ayat Al Quran}

Dalam kitab lain lagi, yaitu Muqoddimah al Qonun al Asasi li Jam'yati Nahdlatil Ulama, Hadratussyaikh mengkritisi soal perkembangan sebuah kelompok Islam yang sangat serampangan dalam menafsiri ayat Al Quran. Berawal dari kesombongan terhadap kemampuan diri sendiri yang tidak mau menerima kaul ulama sebagai pondasi berfatwa, malah mengajak langsung kepada nas $\mathrm{Al}$ Quran dan hadis Rasulullah SAW. Kiai Hasyim mengutip sebagian surat Luqman ayat 15:

“Dan hendaknya Anda mengikuti jejak orang yang menyerahkan semua persoalan yang dikembalikan kepada-Ku (Allah)”, (QS: Luqman: 15)

Dan juga mengutip lagi surat al Anbiya ayat 7:

"Maka hendaklah kalian tanyakan kepada orang-orang yang berilmu, jika kamu tiada mengetahui." (QS: Al Anbiya: 7).

Dari dua ayat itu, Kiai Hasyim ingin memberikan kritik kepada orang-orang yang sembarang memberikan fatwa, dengan jargon kembali kepada Al Quran dan Sunnah, tanpa memperdulikan pendapat-pendapat, intepretasi, istinbath dan istidlal dari para ulama Salaf ash Shalih, dan ulama-ulama lain yang mumpuni. Mereka menafsirkan ayat-ayat sekehendak sendiri, dan semaunya mereka disesuaikan dengan keadaan mereka, sekiranya dapat mendukung problematika mereka. Padahal sudah jelas, ahlu ad Dzikri dimaknai oleh Kiai Hasyim sebagai ulama atau orang-orang alim yang patut menjadi tempat untuk bertanya. Dalam hal ini, ada proses ta'allum dan ta'lim atau belajar mengajar sampai tuntas sebelum mengaku alim.

Kiai Hasyim juga mengutip ayat 36 dalam surat al Isro, di mana Allah memerintahkan umatNya agar tidak mencampuri urusan yang bukan menjadi bidangnya. Terlebih yang dicampuri itu, berhubungan dengan hal-hal pokok dalam agama yang sangat fundamental. Kiai Hasyim mengutip lagi surat Ali Imron ayat 7 yang tentu masih berkesinambungan dalam pembahasan ini. Kiai Hasyim menggunakan ayat ini untuk mengkritik mereka yang mencari-cari ayat-ayat yang serupa dengan maksud untuk dijadikan bahan fitnah (perpecahan sesama umat), dan dengan seenaknya sendiri dalam memberikan arti dan maksud dari ayat-ayat tersebut. Allah menuliskan orang-orang semacam itu, sebagai "alladzinahum fi qulibihim zaighun" manusia yang dalam hati mereka ada itikad tidak baik. ${ }^{21}$

\section{Kritik terhadap Doktrin Kembali kepada Al Quran dan Sunnah}

Masih dalam pembukaan AD/ART NU, Kiai Hasyim mengulang kembali kritikan yang hampir sama, yaitu penolakan secara mentah-mentah terhadap gerakan kembali kepada Al Quran dan Sunnah. Kiai Hasyim mewanti-wanti para ulama NU untuk mewaspadai golongan yang menkampanyekan hal ini. Kata Kiai Hasyim, ada sekelompok orang yang sengaja menyebarkan fitnah di kalangan umat Islam dan melakukan sesuatu di luar ajaran Rasulullah SAW. Namun, Kiai Hasyim juga mendorong orang-orang yang menyadari akan hal itu, tapi memilih diam, agar bertindak dan melakukan gerakan juga. Kiai Hasyim mengatakan:

\footnotetext{
${ }^{21}$ Hadratussyaikh KH. M. Hasyim Asy'ari, Mukaddimah Qanun Asasi Nahdlatul Ulama, (Kudus: Menara Kudus, 1969), hal 15-16.
} 
"Mereka memturabalikkan kenyataan, dan menginkari kebenaran, bahkan mengajak kepada kemungkaran itu. Mereka (kelihatannya) mengaku mengajak kepada Al Quran, tetapi pada hakikatnya mereka sendiri tidak berbuast demikian"

Bahkan Kiai Hasyim menuduh balik mereka sebagai ahli bidah. Lebih tajam lagi, Kiai Hasyim menyebut bahwa mereka mendirikan perkumpulan atau organisasi untuk memperlancar usaha gerakan mereka itu. Terlebih lagi, yang mengikuti mereka dianggap Kiai Hasyim sebagai orang-orang yang tidak mendapatkan hidayah Allah. Kiai Hasyim mengutip hadis Rasulullah SAW:

"(Dalam menuntut ilmu agama Islam), maka lihatlah dari siapa kalian mengambilnya”. ${ }^{22}$

Yang mengikuti ajakan untuk masuk pada perkumpulan-perkumpulan mereka, dianggap oleh Kiai Hasyim sudah tidak lagi mengamalkan hadis tersebut. Maka, sebenarnya Kiai Hasyim ingin mengajak sebaliknya, atau mafhum mukhalafah-nya (pemahaman sebaliknya), yaitu mempelajari dan mengambil pendapat-pendapat para ulama Salaf ash Shalih, bertanya kepada ulama yang dianggap mengerti, ikut dalam pengajian-pengajian dan pengajaran para ulama, serta tidak gampang menyampaikan agama yang sebenarnya tidak dipahami secara tuntas.

\section{Mengajak untuk Memperhatikan Sanad Keilmuan}

Masih dalam Mukadimah Qanun Asasi NU, di bagian Risalah fi Ta'kidi al Akhdz bi Madzahib al A'immati al Arba'ah Kiai Hasyim sekali lagi mengajak untuk memperhatikan prosedur dalam mencari ilmu, yaitu datang kepada para ulama, membaca buku-buku dan literatur yang diwariskan ulama. Tujuannya agar menjaga dan memperhatikan sanad keilmuan agar tidak terputus kepada umat.

Ketika dalam proses belajar kita dilalui dengan prosedur yang benar kepada para ulama, maka tentu ada dua poin yang diperhatikan. Pertama, jalur itu harus melalui sanad yang sahih. Jalan keilmuan itu, artinya, didapatkan dengan berantai dari orang-orang yang terpercaya kebenaran ucapannya, dan perbuatannya. Kedua, sudah terkodifikasikan atau ditulis dalam naskah-naskah kitab atau risalah yang sudah dikenal atau mashur di kalangan umat.

Bahkan, pendapat ulama itu, harus diterangkan mana yang unggul (rajih). Kalaulah pendapat yang bemacam-macam, harus ditakar mana yang paling rajih untuk diikuti. Selain itu, diterangkan pula persoalan yang khusus dari persoalan yang umum (takhshishul 'aam). Tidak cukup itu, persoalan itu harus diterangkan mana yang mutlak dan membutuhkan qoyid. Maksudnya, memberikan batasanbatasan yang menyebabkan suatu persoalan mempunyai kedudukan hukum tersendiri di antara persoalan-persoalan yang masih belum diberikan batasan. Kalaupun ada ikhtilaf di kalangan ulama, harus juga disampaikan ulasannya dan dianalisa sebab-sebab hukumnya. ${ }^{23}$

\section{Kritik Soal Larangan Bermadzhab dan Taqlid}

\footnotetext{
${ }^{22}$ Ibid, hal. 38-39

${ }^{23}$ Ibid, hal. 56-58
} 
Masih dibagian kedua dari Mukadimah Qanun Asasi NU. Sudah jamak diketahui bahwa NU sendiri memiliki panutan dalam bermadzhab fikih, yaitu Hanafi, Maliki, Syafi'i dan Hanbali. Apakah tidak ada madzhab yang lain dalam sejarah fikih Islam? Tentunya ada. Ada beberapa ulama yang disebut telah sampai pada derajat mujtahid muthlak, yang berhak menjadi acuan dalam berfikih, seperti Imam al Laits bin Sa'ad pendiri Madzhab al Laitsiyah, Daud ad Dhahiry pendiri Madzhab Dhahiriyah, Imam Abu Ja'far dengan Madzhab Ja'fariyahnya, Zaid bin Ali dengan Zaidiyahnya, Imam Sufyan ats-Tsauriy, al Auza'iy, Ibn Jarir ath Thabari, Sufyan bin Uyainah, Ishak bin Rawaihi, ada juga Madzhab Imamiyah, dan masih banyak lagi.

Namun, menurut Kiai Hasyim, empat madzhab yang paling berhak untuk diikuti, bukan karena tidak mumpuni untuk diikuti. Dalam pembahasan sebelumhya, dijelaskan Kiai Hasyim, sebabnya, karena sanadnya terputus, akhirnya susah untuk diikuti. Selain itu, karya-karya besar imam madzhab selain yang empat itu tidak terkodifikasikan dengan baik. Para murid dan pengikut mereka juga ikut serta berkontribusi dalam penyebaran ajaran-ajaran imam empat itu. Khusus untuk Imamiyah dan Zaidiyah, karena mereka sempalan Syiah, Kiai Hasyim menyebutnya ahli bidah dan tidak boleh diikuti.

Karena terjaganya sanad keilmuan dan kodifikasi yang baik dalam empat madzhab, maka diikuti oleh mayoritas umat atau golongan terbanyak (as Sawadu al A'dham). Yang mengikuti golongan selain empat itu, dianggap keluar dari golongan terbanyak dari umat. ${ }^{24}$ Lah maksud dari menerangkan ini, Kiai Hasyim ingin mengkritik golongan yang ingin menghapuskan sistem madzhab dengan jargon kembali kepada Al Quran dan Sunnah. Selain karena pengaburan isnad keilmuan, gerakan ini ingin menghapuskan great mujtahid muthlak dan menggantinya dengan fatwa-fatwa yang istidlal-nya seenaknya saja. Ulama-ulama mereka tidak memiliki kualifikasi mujtahid muthlak, sehingga bagi Kiai Hasyim tidak patut memantas-mantaskan diri untuk memaksakan ijtihad untuk umat, apalagi memaksanakan madzhab tunggal mereka kepada umat.

Selain menghapus sistem bermadzhab, golongan ini juga melarang taklid terhadap madzhab-madzhab itu. Padahal orang-orang awam agama, jauh untuk menggapai derajat mujtahid. Bagi Kiai Hasyim, orang-orang awam itu boleh berlaku taqlid terhadap madzhab itu, karena keawaman mereka. Kalau orangorang awam itu diizinkan untuk ber-istidlal dengan segala keterbatasan mereka, tentu malah menimbulkan kerusakan pemahaman.

Mengomentari pendapat Ibn Hazm bahwa taqlid (mengikuti orang lain, tanpa mengetahui alasannya), itu hukumnya haram, Kiai Hasyim menggarisbawahi maksudnya. Keharaman itu, dimaksudkan untuk orang-orang yang memiliki kemampuan berijtihad, meskipun hanya dalam satu persoalan. ${ }^{25}$ Bahkan, beliau mengatakan bahwa hal itu menjadi wajib bagi seseorang yang bukan mujtahid mutlak untuk taklid kepada suatu madzhab tertentu dari madzhab empat. Tidak boleh langsung mengambil dalil (istidlal), baik dari ayatayat Al Quran maupun hadis. Dasar dari pendapat beliau adalah ayat:

\footnotetext{
${ }^{24}$ Ibid, hal. 59

${ }^{25}$ Ibid: hal. 63
} 
"Dan kalau mereka menyerahkannya kepada Rasul dan Ulil Amri di antara mereka, tentulah orang-orang yang ingin mengetahui kebenarannya (akan dapat) mengetahuinya dari mereka (Rasul dan Ulil Amri)." (QS: an Nisa: 83).

Maksudnya, Kiai Hasyim ingin menyampaikan bahwa mereka yang dimaksud Ulil Amri orang-orang yang dianggap kuasa atau mampu menghendel kepentingan umat Islam, baik dunia dan akhiratnya. Mereka inilah yang tentu lebih tahu persolaan umat. Maka sudah jelas, mereka yang berhak melakukan istinbath hukum ialah orang yang yang ahli ijtihad, tidak sembarangan orang. ${ }^{26}$

\section{Diskusi Analisis Sosio Historis Politis}

Di antara beberapa referensi Kitab Kiai Hasyim yang mengandung kritikan terhadap ajaran dan gerakan Wahabisme, hanya an Nur al Mubin fi Mahabbati Sayyidi al Mursalin saja yang dicantumkan tanggal selesai ditulisnya, yaitu pada 25 Sya'ban 1346/17 Februari 1948. Selainnya, misal Risalah Ahlussunnah wa al Jama'ah, Qanun Asasi NU, Risalah fi Taakudi al Akhdz bi Madzahibi al Aimmati al Arba'ah, Jawa zat Taqlid, dan lainnya tidak dicantumkan kapan kepenulisannya diselesaikan.

Namun, dilihat dari perkembangan Wahabi yang telah melalui sejarah yang cukup panjang agar dapat berkembang di Jazirah Arab, tentu perlu dianalisis mendalam. Wahabi muncul ketika terikrarnya Muhammad bin Abdil Wahab sebagai imam dan Ibn Saud sebagai emir di Dir'iyah pada $1744 .{ }^{27}$ Sampai pada tahun 1818 kerajaan ini bertahan dengan Kesultanan Nejad, atau sekarang dikenal dengan Negara Saudi Pertama (al Arabiyah as Sa'udiyah al 'Ula).

Pada 1818 diambil alih Mesir di bawah komando Turki Usmani dipimpin Muhammad Ali Pasha dan putranya Ibrahim, ${ }^{28}$ tetapi bertahan hanya enam tahun sebelum akhirnya ditakhlukkan lagi sebagian wilayahnya oleh Wangsa Saud, disebut Negara Saudi Kedua (al Arabiyah as Sa'udiyah ats Tsaniyah). Wangsa Saud dipimpin Turki ibn Abdallah ibn Muhammad ibn Saud, menakhlukkan kekuasaan Mesir dan Turki Usmani pada 1923/1924. ${ }^{29}$ Negara ini hanya menguasai wilayah Timur saja (sekarang meliputi wilayah Arab Saudi, Bahrain, Uni Emirat Arab, Qatar dan Oman) dan bertahan dari tahun $1824-1891 .^{30}$ Negara ini lalu ditakhlukkan oleh Emirat Jabal Shammar (Emirat Ha'il) sampai tahun 1921 oleh Wangsa Rasyid (pusat di Riyadl Utara). ${ }^{31}$

Wangsa Saud sebenarnya bangkit masih eksis dengan nama Emirat Nejd dan Hasa dari tahun 1902-1921 atau Negara Saudi Ketiga (al Arabiyah as Sa'udiyah al Tsalitsah) hanya meliputi wilayah Nejed dan Hasa. Sebelum akhirnya

\footnotetext{
${ }^{26}$ Ibid, hal. 65-66

${ }^{27}$ Syaikh Idahram, Sejarah Berdarah, Sekte Salafi Wahabi: Mereka Membunuh Semuanya, termasuk Para Ulama, (Bantul: Pustaka Pesantren, 2011), Cet. XVII, hal. 39

${ }^{28}$ James Wynbrandt, A Brief History of Saudi Arabia, (New York: Foreword by Fawaz A. Gerges, 2010), Cet. 2, hal. 142

${ }^{29}$ Ibid, hal. 148-150

${ }^{30}$ Madawi Al-Rasheed, A History of Saudi Arabia. Cambridge, (England, UK: Cambridge University Press, 2002), hal. 23

${ }^{31}$ Ibid, hal 25.
} 
menakhlukkan lagi wilayah Kerajaan Hijaz (1925) dan Emirat Ha'il 1921). Masamasa ini disebut masa Univikasi Arab antara tahun 1902-1932 $2^{22}$, yang bertransformasi dari Emirat Nejed dan Hasa (sampai 1921), Kesultanan Nejed (1921-1932), Kerajaan Univikasi Nejed dan Hijaz (18 September 1932).

Baru diakui oleh dunia internasional sebagai Kerajaan Arab Saudi yang menguasai sebuah wilayah negara yang absolut pada 23 September 1932. ${ }^{33}$ Maka 188 tahun, atau hampir dua abad lamanya Saudi-Wahabi mengusahakan berdirinya negara Arab Saudi dengan paham tunggalnya. Maka bisa dipastikan, bahwa Kiai Hasyim yang belajar di Mekkah dalam kurun waktu 1892-1899 pastinya bersinggungan dengan gerakan ini. Walau pada masa 1991-1921 Hijaz di tangan Turki Usmani-Mesir, namun pengaruh perkembangan ajaran ini cukup menghawatirkan, karena bersinggungan langsung dengan wilayah Nejed yang dikuasai Wangsa Saud di Timur.

Thaif takhluk oleh militer Kerajaan Saudi pada 1803. Syarif Ghalib, penguasanya tumbang. Lalu, pada tahun 1803-1804 Mekkah al Mukarramah sudah takhluk. Berlanjut ke Riyadl, Yaman, Bahrain, Kuwait, Karbala dll. Bisa dikatakan, abad 18-19 Jazirah Arab telah dipengaruhi oleh paham Wahabi yang dibawa oleh penguasa Saudi kala itu. Pemaksaan terhadap madzhab Wahabi kepada ulama dan umat Islam di sana, serta upaya untuk menghilangkan tradisi keilmuan yang sangat menganggungkan sanad oleh mereka menjadi diskursus utama pada saat itu. Walau kekuasaan itu masih naik turun, sebab adanya kekuatan besar Turki Usmani, persinggungan Wahabi dan umat Islam di Jazirah Arab sudah kental.

Apalagi saat itu gencar-gencarnya gerakan Pan Islamisme dan pembaharuan Islam yang diusung oleh Rasyid Ridho, Jamaluddin al Afghani, dan Muhammad Abduh, turut mewarnai pemikiran pelajar Islam di Haramain. Diskusi soal itu, gencar dilakukan. Muhammad Abduh yang berpaham reformis, modernis, dan ingin memurnikan ajaran Islam, sudah sampai dan berpengaruh di Nusantara, khususnya di Sumatera Barat melalui mereka yang pulang dari haji dan belajar di Mekkah. Kemudian di Jawa ada KH. Ahmad Dahlan dengan Muhammadiyahnya.

Kiai Hasyim melihat sebenarnya pemikiran Abduh sangat bagus untuk kebangkitan umat Islam, menegakkan Islam atas kesewenang-wenangan kolonialisme selama beradab-abad. Tapi ajaran memurnikan Islam, dan penghapusan praktek bermadzhab menjadi titik keberatan Kiai Hasyim.

Puncak dari kekhawatiran Kiai Hasyim dengan perkembangan pesan Wahabi adalah pada kurun waktu 1918-1926 di mana Hijaz dikuasai penuh oleh Wangsa Saud, banyak terjadi upaya-upaya Kerajaan Saudi untuk melakukan kegiatan-kegiatan yang menyulut emosi umat Islam di dunia. Di antaranya, menjadikan madzhab Wahabi sebagai madzhab tunggal dan resmi negara, rencana penghancuran peninggalan sejarah Islam yang selama ini diziarahi umat Islam karena dianggap bidah, dan yang paling menimbulkan reaksi besar yaitu rencana pembongkaran makam Rasulullah SAW.

\footnotetext{
${ }^{32}$ James Wynbrandt, A Brief History of Saudi Arabia, (New York: Foreword by Fawaz A. Gerges, 2010), Cet. 2, hal. 180

${ }^{33}$ Ibid, hal. 187
} 
Yang membuat Kiai Hasyim lebih khawatir adalah, ada kelompok umat Islam di Jawa saat itu, yang mendukung upaya Kerajaan Saudi, seperti Sarekat Islam dan Muhammadiyah. Tokoh-tokoh modernis seperti HOS Tjokroaminoto dan KH Ahmad Dahlan mendukung sekali hal itu. Sebaliknya, kalangan pesantren justru menganggap hal itu sebagai ancaman untuk keberagaman, kebebasan bermadzhhab, dan merusak warisan peradaban, tradisi dan budaya Islam.

Hal itu lalu menjadi latar belakang NU didirikan pada 1926 diawali dengan adanya Komite Hijaz yang direstui oleh Kiai Hasyim menjadi duta negosiasi agar upaya-upaya itu digagalkan. Pengaruh Wahabi juga akhirnya sampai di Mu'tamar Alami al Islami (Kongres Islam Internasional) di Mekkah, tempat akan disahkannya rencana-rencana Saudi itu. Saudi tidak melibatkan kalangan pesantren dalam kongres itu, akibat penolakan yang dilakukan kaum pesantren, terlebih lagi mereka sudah di-DO dari organisasi Kongres Al Islam.

Kiai Hasyim didesak untuk segera merestui terbentuknya Komite Hijaz, yang selanjutnya menjadi cikal bakal NU. Kiai Hasyim menjadi legitimator jamiyah itu, sedangkan Kiai Wahab sebagai eksekutor dan organisator yang mengurus jalannya organisasi bersama Kiai Bisri Sansuri, Hasan Gipo, Kiai Mas Alwi, Kiai Abdullah Ubaid, dan kiai-kiai pesantren yang lain.

Latar belakang ini tentu menjadi jelas, kenapa Kiai Hasyim mengkritik pemikiran aliran pembaharu Islam, khususnya Wahabi dan turunan-turunanya. Namun yang paling penting adalah, fakta bahwa Kiai Hasyim merupakan putra asli produk pesantren. Lahir di pesantren, besar di pesantren, dan menjadi pengasuh pesantren. Pesantren adalah ikon Islam tradisionalis, mengakomodir budaya dan tradisi yang masih relevan dengan Islam, serta kuat dalam menjaga sanad keilmuan.

Namun, pertanyaannya kenapa Kiai Hasyim tidak menuliskan kritikan demi kritikan itu dalam satu bendel kitab atau risalah? Kenapa harus terpencar dalam beberapa risalah dan kitab? Wallau a'lam. Namun, kepenulisan Kiai Hasyim, sering kali karena adanya peristiwa atau kejadian yang menarik perhatian beliau, menuliskannya menjadi catatan, bahkan buku. Barangkali, ada lain yang melatarbelakangi hal itu, misalkan saja, agar tidak menimbulkan kekaduhan di kalangan umat yang saat itu sudah tergaduhkan. Penderitaan akibat kolonial juga masih berlangsung. Apalagi, persatuan umat terus menjadi pesan utama beliau.

Kemudian, cara beliau menuliskan kritikannya juga menarik untuk dibahas. Pertama, menjaga identitas yang dikritik. Beliau tidak langsung menyebut nama organisasi tersebut, bahwa nama Wahabi saja tidak disebutkan. Nama Muhammad ibn Abdul Wahab hanya disebutkan sekali dalam kitab an Nur al Mubin saja. Kasus ini berbeda, ketika beliau menyebut Ibn Taimiyah yang cukup panjang dibahas dalam kitab itu. Bisa jadi karena ia yang menjadi spirit dan ide dasar Wahabi.

Kedua, tidak frontal. Untuk konteks Wahabi, Kiai Hasyim tidak begitu frontal, bahkan untuk syi'ah sekalipun. Paling keras, hanya mengatakan ahli bid'ah saja, apalagi sampai mengatakan kafir. Ketiga, mengkonter dengan dalil yang dipakai oleh golongan yang sedang dikritik. Misal menggunakan ayat atau hadis yang dipakai Wahabi untuk mengkonter balik. Di atas sudah ada beberapa contoh. 
Keempat, tidak memberitakan kasus dan fenomena yang sedang terjadi secara rinci, hanya menyebut "ada golongan" atau "inna qauman" dst. Hal ini sejauh yang penulis pahami dari tipologi kritik Kiai Hasyim terhadap ajaran Wahabi. Wallahu a'lam bishshawab.

\section{Simpulan}

Seperti dijelaskan di atas oleh peneliti menunjukkan bahwa ada beberapa poin yang menjadi titik kritik KH. Hasyim Asy'ari terhadap ajaran-ajaran Wahabisme. Wahabi menggunakan nama Salaf untuk mendekatkan diri pada objek dakwahnya, seakan-akan mengacu pada hadis riwayat Bukhori Muslim tentang siapakah generasi salaf itu, yaitu generasi sahabat, tabiin, dan tabiit tabiin. Setelahnya lalu disebut generasi khalaf.

Kiai Hasyim melakukan kritik dalam beberapa kitabnya, seperti kitab Risalah Ahlussunnah wal Jama'ah, Nur al Mubin fi Mahabbati Sayyid al-Mursalin dan Muqaddimah Qanun Asasi. Ada setidaknya 8 poin yang menjadi titik persinggungan kritik Kiai Hasyim atas pemikiran pembaharuan yang diusung Wahabi, yaitu: (1) pemaknaan istilah "bidah", (2) mengaku sebagai pengikut Ibn Taimiyah, (3) doa bagi mayit tidak sampai, (4) syafaat tidak ada, (5) sembrono dalam menafsiri ayat Alquran, (6) doktrin kembali ke Alquran dan Sunnah, (7) tidak memperhatikan sanad keilmuan, (8) larangan bermadzhab dan taqlid.

Ada empat cara Kiai Hasyim dalam melakukan kritik Pertama, menjaga identitas yang dikritik. Kedua, tidak frontal. Ketiga, mengkonter dengan dalil yang dipakai oleh golongan yang sedang dikritik. Keempat, tidak memberitakan kasus dan fenomena yang sedang terjadi secara rinci, hanya menyebut "ada golongan" atau “inna qauman" dst.

Tentu memerlukan kajian lebih mendalam tentang kritik-kritik KH. M. Hasyim Asy'ari terhadap aliran-aliran baru yang pada saat itu (saat Kiai Hasyim hidup) muncul. Kritik-kritik tersebut lebih dapat dipakai sebagai sebuah interaksi keilmuan para ulama pendahulu, dan bagaimana mereka melakukan kritik. Sebagai pengawal organisasi keagamaan Islam yang mewakili kemoderatan atau wasathiyah, Kiai Hasyim patut untuk digali sebagai bentuk usaha dalam memadukan keislaman dan keindonesiaan. Perlu diperbanyak kajian-kajian tentang pemikirannya, agar generasi selanjutnya tidak melupakan ajaran-ajaran ulama-ulama panutan di masa lalu, untuk menjaga persatuan umat dan bangsa Indonesia. 


\section{DAFTAR PUSTAKA}

Al-Rasheed, Madawi. 2002. A History of Saudi Arabia. Cambridge. England UK: Cambridge University Press.

Asy'ari, Hadratussyaikh KH. M. Hasyim. Risalah Ahlussunnah wa al Jama'ah. Jombang: Pustaka Warisan Islam.

. an Nur al Mubin fi Mahabbati Sayyidi al Mursalin. Jombang: Pustaka Warisan Islam Tebuireng. Kudus, 1969. 1969. Mukaddimah Qanun Asasi Nahdlatul Ulama. Kudus: Menara

Diyab, Muhammad Hafidz. 2015. Asalafiyun wa as Siyasah. Kairo: al Haiah al Misriyyah al Ammah li al Kitab.

Idahram, Syaikh. 2011. Sejarah Berdarah, Sekte Salafi Wahabi: Mereka Membunuh Semuanya, Termasuk Para Ulama. Bantul: Pustaka Pesantren.

Majid, Nurchalis. 2008. Islam, Kemoderenan, dan Keindonesiaan. Bandung: Mizan.

Maskumambang, Muhammad Faqih Ibn Abdul Jabbar, an Nushush al Islamiyah $f i$ Raddi ala Madzhab al Wahabiyah. 2016. Bogor: Sahifah li ath Thiba'ah wa an Nasyr.

Mubarok Yasin, Ahmad, \& Fathurrohman Karyadi. 2011. Profil Pesantren Tebuireng. Jombang: Pustaka Tebuireng.

Mukani. 2015. Biografi dan Nasihat Hadratussyaikh KH. M. Hasyim Asy'ari. cet 1. Jombang: Pustaka Tebuireng.

Rusli, Ris'an. 2014. Pembaharuan Pemikiran Modern Dalam Islam. Jakarta: Rajawali Pers.

Taimiyah, Ibnu. 1980. Majmu'atu al Fatawa. Jilid III. Beirut: Dar el Fikr.

Wynbrandt, James. 2010. A Brief History of Saudi Arabia. Cet. 2. New York: Foreword by Fawaz A. Gerges. 